\title{
The science of pesticide-free potato chips
}

$\mathrm{T}$ here is no question that the organic food industry is booming. Even junk food makers are clambering aboard the organic train, as a quick walk through the aisles of almost any supermarket demonstrates. Now available? Organic chocolate bars. Organic jelly beans. Even organic potato chips.

What was once a niche market has become such a juggernaut that Research and Markets, the Ireland-based international market research provider, projects global revenues now range in the neighbourhood of US\$60 billion per year, having experienced a compound annual growth rate of about $11 \%$ between 2006 and 2010 (www.research andmarkets.com/reports/2001395/global _organic_food).

Simply put, that's a whole lot of pesticide-free lettuce.

The public perception appears to be that organic foods are better, having been grown under strict conditions of purity that preclude the use of toxic agricultural chemicals such as synthetic pesticides, or growth hormones or antibiotics, in the case of animals like cows and chickens. Ergo, they must be "healthier" or more nutrient rich than conventionally produced fare, or, at a very minimum, free of traces of nasty compounds.

But is there any concrete evidence in support of that proposition?

Not much, if any, according to independent experts.

Tons, according to the organic food industry and organic devotees.

None of the evidence makes anything like a compelling case that there is any difference between organic and nonorganic foods, says Joseph Rosen, professor emeritus of food toxicology at the School of Environmental and Biological Sciences at Rutgers University in New Brunswick, New Jersey. "The clear advantage for conventional food is that it doesn't cost nearly as much as organic food. Health-wise, people are just fooling themselves."

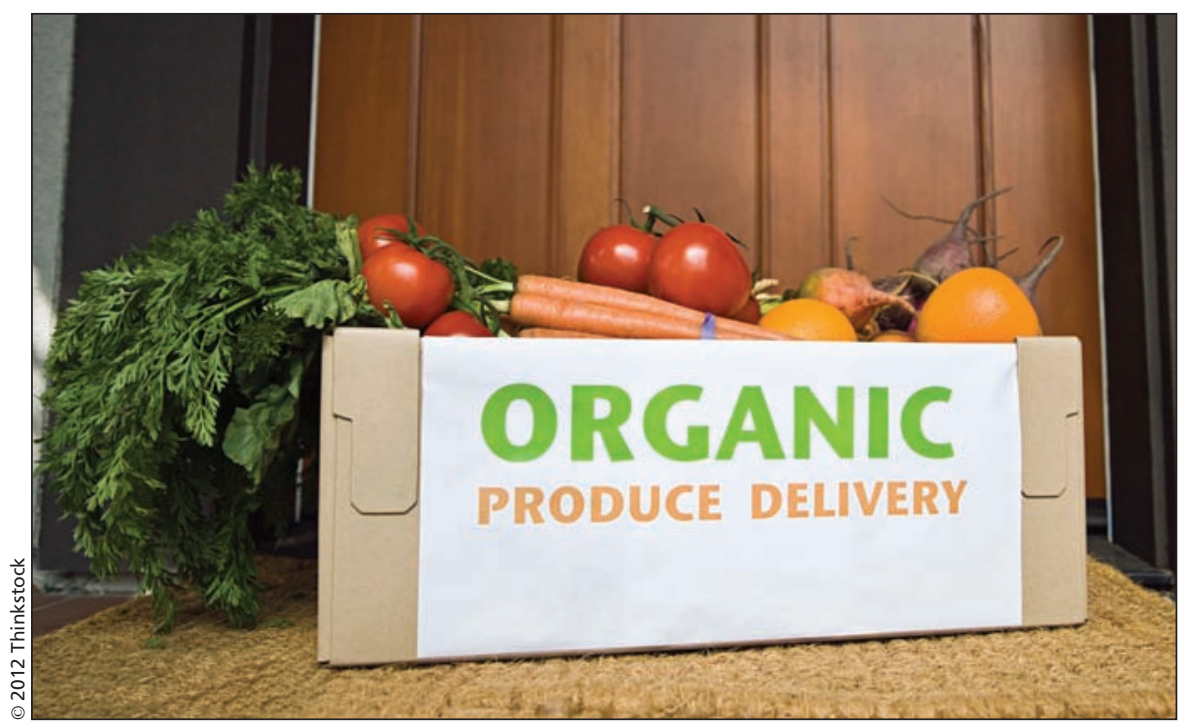

Many consumers turn to organic foods because they fear the deleterious effects of pesticides.

That's certainly supported by a pair of systematic reviews on the nutritional quality and health effects of organic foods. Funded by the United Kingdom's Food Standards Agency, the former indicated that while "a small number of differences in nutrient content exist between organically and conventionally produced foodstuffs and that, whereas these differences in content are biologically plausible, they are unlikely to be of public health relevance" and most likely related to differences in production methods (Am J Clin Nutr 2009;90:680-5). The systematic review of health effects, meanwhile, concluded that "evidence is lacking" for the proposition that organic foods have health benefits (Am J Clin Nutr 2010; 92:203-10).

But the fact there's no evidence that traces of pesticides and other contaminants have a deleterious effect on health doesn't allay public fears, notes Ruth Kava, a registered dietitian and senior nutrition fellow at the American Council on Science and Health. "Some consumers are frightened of any chemical they can't pronounce. The thought that pesticides of any sort are dangerous to some critter out there, they tend to think that means they're also dangerous to humans."

The organic food industry and organic food advocates, of course, beg to differ with the conclusions of the systematic review, which they assail as the tools of the food, pharmaceutical and biotechnology industry, while pointing to their own "state of science review" as evidence of superior science. Entitled New Evidence Confirms the Nutritional Superiority of PlantBased Organic Foods, it concluded that "the magnitude of the differences in nutrient levels strongly favored the organic samples" and that the nutritional differences were such that organic crops contained, on average, $25 \%$ more nutrients than the conventionally grown variety (www.organic -center.org/reportfiles/5367_Nutrient _Content_SSR_FINAL_V2.pdf).

But those are conclusions that smack of financial self-interest, says Rosen. "Exactly what do you expect them to report when they're working for people who would like to sell as much organic food as possible?"

Organic food advocates counter that while it's impossible to guarantee that consumption of their products is a 
ticket to better health, they believe there are benefits. "I don't think any of us involved in organic food and farming in North America, Europe or anywhere else in the world would claim that you'll definitely be healthier if you eat organic food," says Peter Melchett, policy director of the Soil Association, a UK-based environmental advocacy group. "What we would say ... is there's good scientific evidence that you're going to have more beneficial nutrients and avoid some potentially harmful substances."

The general populace certainly seems convinced. An online survey conducted by Nielsen, a global marketing and advertising research group, in 2010 indicated that $76 \%$ of consumers bought organic products because they believed them to be healthier, $53 \%$ to avoid pesticides and other toxins, and $51 \%$ because organic food is more nutritious (http://blog.nielsen.com /nielsenwire/consumer/global-trends -in-healthy-eating/).

In short, from the public's perspective, the evidence has become almost irrelevant.

And that's become the norm in the debate over the value of organic and nonorganic foods, Kava says, citing as an example the claim that the former have higher antioxidant content, which can destroy "free radicals" that are believed to cause cancer. But there's no evidence that such nutrients have a positive effect in humans, she says. "This is another really great marketing term. You can, in a test tube, determine that one type of food ingredient or food has greater antioxidant potential, but that's a different thing than having it in the body where there are a lot of different interacting molecules."

Consumers of organic foods are essentially acting on faith, Kava says. "I tend to think that people make this kind of choice based on what they want to believe rather than what's really out there. It's not as though this is going to be harmful to their health. It may be harmful to their pocketbooks, but it's something that can move the market if enough people take it as a given."

"If people feel better because they're eating organic, fine - that's their choice if they can afford it. I personally don't think there's any great value for their money, but again, it's a free country," Kava adds. — Michael Monette, CMAJ

CMAJ 2012. DOI:10.1503/cmaj.109-4290 